\title{
TITO CASINI \\ ESCRITOR POR VOCAÇÃO
}

\author{
Luigi Castagnola \\ (Catedrático de Língua e Literatura Italiana na \\ Universidade do Paraná)
}

Tito Casini pertence a um grupo de escritores toscanos e católicos que teve notável ressonância em tôda a Itália na primeira metade dêste século. No entanto, estêve sempre fora de qualquer escola literária. O que o prendeu a determinados amigos e escritores de sua terra foi o amor às letras e à religião. Não há outro escritor italiano com quem tenha êle semelhanças estilísticas, e também seu mundo artístico é inteiramente pessoal. Não imitou a ninguém e ninguém o imitou; amigo de todos e independente de todos. Por êste motivo Tito Casini tornou-se uma voz nova no meio da literatura italiana contemporânea.

Casini é artista e escritor por vocação. Entretanto, quando resolveu ingressar numa universidade, não escolheu a faculdade de letras, mas a de direito. Estranho fenômeno revela a história da literatura italiana: em grande número, poetas e literatos da Itália saíram das faculdades de direito e deixaram a advocacia para entregar-se às letras e à poesia. Assim fizeram Pier della Vigna, Giacomo da Léntini, Jacopone, Guinizelli, Cino da Pistoia, Petrarca, Boccaccio, Ariosto, Guicciardini, Tasso, Marino, Metastasio, Vico, Goldoni, Monti, Giusti, Fogazzaro, Cicognani e muitos outros. Casini continua essa tradição. Entretanto, diversamente de quase todos êsses literatos peninsulares, que começaram, de má 
vontade, indo atrás de deusa Têmis, cursou a faculdade de direito com dedicação e brilho, e deu o adeus aos códigos sòmente depois de sua formatura.

"Eram due mesi che il professore, senatore eccetera eccetera David Supino, rettore della regia università di Pisa, visto il risultato dell'esame di laurea da me sostenuto, mi aveva proclamato dottore in giurisprudenza, e nessuno ancora aveva fatto ricorso al mio dottorato, allorchè, una sera - ero sull'aia con Virgilio, i cui esametri mi rimettevan lo stomaco dal barbaro latino delle Pandette -, venne da me Pinella per chiedermi che lo difendessi" (1).

Pianella era um borrachão de Cornacchiàia, o torrão natal do escritor; o chefe dos carabineiros surpreendeu-o, em estado de plena embriaguez, a molestar os transeuntes da rua e intimou-lhe que comparecesse à polícia para se defender da contravenção infligida pelo código penal. $O$ beberrão lembrou-se do neo-advogado que, dois meses antes, êle saudara "honra do povo e da comuna" e foi procurá-lo a fim de que o defendesse. Embora the parecesse pouco elegante começar sua carreira forense com uma causa de embriaguez, Casini aceitou por se tratar de um pobre diabo da sua gleba natal, homem do povo e cantor de igreja, que lhe tinha sempre devotado grande cordialidade. A defesa do advogado foi excelente $e$ as coisas correram bem para aquêle aldeão que se gabava de ter transformado sua barriga em tonel. Mas, desde então, Casini não quis mais saber de advocacia. A Itália teve, assim, um causídico a menos e um escritor a mais.

Já dissemos que Tito Casini é filho da Toscana, a região italiana que deu à península a sua língua e é a mais fértil em artistas e escritores. Nasceu em 1897, em Cornacchiàia, aldeia cravada num vale do Apenino toscano, não muito distante de Florença. Casini, homem de letras, esclarecerá os seus leitores sôbre a origem antiga e nobre do nome de sua pátria, Cornacchiàia, "brutto nome ma caro paese". Outrora chamava-se Cornuaclara, pelas colinas sempre claras e serenas: claras no verão pela luz do sol, claras na primavera pelas flô- 
res silvestres, e claras também no outono pelas nuvens brancas e até no inverno pelas neves alvinitentes. Aquêle bonito nome latino, por corrupção, mudou-se na forma atual de Cornacchiaia, que "fa pensare e un uccello nè per le penne nè per il canto nè per i costumi gradevole" (2).

Pertence a uma família de abastados proprietários de terras. O pai, Fernando Casini, era o tipo do patriarca à antiga.. "Sia per la sua alta e bella presenza - escreve Severino Monticone -, sia per il buon senso e la nobiltà del suo animo, egli dominava e comandava. Era un bell'uomo, gagliardo, sempre corretto nel suo dire, risoluto negli ordini che impartiva, e la distribuzione delle occupazioni era sempre regolata da lui nè si violava impunemente" (3). A mãe, Umilina Biondi, era um modêlo de espôsa; espírito delicado e carinhoso, de saúde um tanto abalada, dedicava-se com ternura aos cuidados do lar. Faleceu aos quarenta anos de idade, num hospital de Florença. Mais tarde morreu também o pai, cuja perda o escritor sentiu profundamente. Em "I Giorni del Ciliegio" compara a morte do pai ao desaparecimento do grande carvalho que, durante séculos, tinha crescido perto da casa paterna.

"V'era, fino a poco addietro, presso la nostra casa una querce, alta di fusto e vasta di ramatura come i molti secoli e il propizio terreno l'avevan fatta, sotto i cui bracci, pieni a suo tempo di nidi e sempre di canti, si poteva sicuramente riparare cosí dal sole come dall'acqua, mentre d'inverno, nell'ora dolce delle veglie, il focolare ardeva sempre, con lieti chiocchi, di qualche suo dono. Cadde un giorno la querce, che al vento non aveva mai piegato, e tanto lasciò in sua vece di spazio che a tutti pareva, non una pianta, ma un intero bosco si fosse tolto dal suolo.

Sicura e lieta nella larga ombra vostra riparava dai danni del tempo la mia piccola vita, beandosi della poesia che dalla bocca vostra - narrasse fatti o leggende - usciva come dai rami il canto degli uccelli" (4). 
Exerceu notável influência sôbre a formação do futuro literato também um tio padre, Estévão Casini, vigário de Cornacchiaia. Austera figura de sacerdote, dedicou tôda a sua existência ao ministério religioso entre 0 povo humilde da aldeia. Reconstruiu a matriz e escreveu "Il Libro dei Martiri".

"L'antica chiesa di Cornacchiaia (la mia chiesa), la prima e la madre delle chiese cristiane del nostro Appennino, edificata e consacrata da san Zanobi, era da due anni in ricostruzione allorchè il pievano pubblicò il suo libro dei Martiri. L'impresa bella e gloriosa, di riportare la vecchia pieve all'antica forma e vastezza quale l'aveva lasciata, dadicandola alla Madonna, la contessa Matilde, e l'aveva visitata, operandovi un de' suoi miracoli, l'arcivescovo sant'Antonino, aveva avuto principio con la benedizione e l'accensione della fornace il 2 luglio, festa della Visitazione, del 1901... A dar fuoco, con una candelina, alle legna già preparate sotto una prima volta di sassi da calcinarsi, ero stato scelto io, che avevo allora tre anni e mezzo" (5).

Durante o dia trabalhava com o povo na reconstrução da matriz e, de noite, ia compondo o livro dos mártires. "Era come un'altra chiesa che sorgeva, anzi risorgeva, un po' per notte, davanti al suo spirito; una chiesa fatta di meriti, cementata col sangue, di cui l'altra, a pietre e calcina, poteva dirsi un'immagine, una figura sensibile" (6).

Casini começou a estudar na sua vila e distinguiu-se entre os alunos pela facilidade com que fazia suas composições. Detestava, porém, a matemática e teve grande alegria no dia em que soube que Carducci, Pascoli e D'Azeglio haviam sido alunos fraquejantes na arte dos números.

Passou a infância na vasta casa patriarcal dos "Poggini Rossi" e foram seus brinquedos não a bugiganga de matéria plástica, com que se atoleimam as crianças crescidas nas colmeias malcheirosas de concreto, mas os cavalos, os cachorros, as ovelhas, os grilos, as flôres, os caniços, as vassouras, 
as pedras, o barro e a água; sua palestra foram os vales e os montes. A casa de "I Poggini Rossi" tinha também uma capela de pedras, construída pela fé dos avoengos, onde Casini fol acostumado a cultuar Deus e respeitar os homens. Os trabalhos do campo e as festas da igreja impressionaram de um modo benfazejo o futuro poeta geórgico e litúrgico.

"Crescendo tra bifolchi, pastori e carbonai, gente che viveva, con schietta serenità e con tenace amore, la vita della terra, si iniziò la sua vita di fanciullo campagnolo... La campagna lo educò quanto la scuola. Quella sua certa e determinata campagna. Tutto quel che c'è di poetico, di delicato, de nostalgico in lui, l'ha avuto dalla campagna. S'inebriò di sole, respirò l'odor dei prati e dei boschi. Tra i contadini, gente silenziosa, piena di segreti... si forma l'anima georgica del fanciullo, che si trasformerà poi nelle manifestazioni più perfette delle narrazioni dello scrittore. Si sentirà poeta, poeta di quella vita che ha vissuto con tanto trasporto e abbandono" (7).

Os anos da infância ficaram gravados profundamente no espírito do escritor. Sua obra literária faz reviver todos os recantos de sua terra, seus montes, seus campos, seus homens de trabalho e de fé: lavradores, mateiros, pastôres, carvoeiros, negociantes ,braceiros, donas de casa e moças de aldeia. Casini teve, ao longo de sua vida, uma saudade imensa de seu torrão natal, de seu berço desfeito. Na sua produção literária vivem de novo tôdas estas coisas, e o escritor nunca teve a coragem de se afastar corporalmente dos lugares onde viveu quando criança. um homem, um literato arraigado ao solo natal como uma pedra, como um carvalho.

Seu primeiro vôo deu-o em 1906. Foi para perto: Firenzuola. Ai estudou alguns anos e terminou o curso ginasial, brilhando como aluno de lingua e literatura italiana. Ampliou seus conhecimentos literários, teve sólida formação humanista, apoderando-se do latim e apreciando as literaturas estrangeiras, especialmente a francesa e a russa. $O$ segundo vôo foi para um pouco mais longe, mas não muito: Florença. $\mathrm{Na}$ grande pátria dos artistas, na cidade que viu nascer o maior poeta da Itália, Dante Alighieri, entrou em 1914 para 
cursar o liceu. A primeira guerra mundial arrancou Tito Casini dos estudos clássicos e, com pesar, teve êle que deixar de lado o amado Virgílio para pegar no fuzil. Bom patriota, cumpriu com seu dever de soldado, embora detestando a guerra. Ingressou para o exército como simples pracinha e foi enviado para perto de Bolonha. Pouco tempo depois, já oficial, ia para o campo de batalha, para o reino do ódio e do sangue, tão diferente do reino da paz de Cornacchiaia, tão diverso do reino do amor e da fé, que êle haveria de enaltecer em suas obras futuras. Numa batalha foi ferido numa perna e no braço direito por estilhaços de granada. 'Il braccio destro - conta Monticone - restò offeso in modo da non potersene più servire per quel che vuole, neppur per scrivere, che sarebbe l'affare principale per il suo mestiere, come chiama lui la professione di scrittore" (8). Sua contribuição para a guerra não estava, porém, acabada. Reestabelecido na saúde, foi enviado para a Albânia, onde apanhou as febres malignas. Desembarcado num hospital do litoral italiano, foi submetido a operações cirúrgicas e, depois de ter ficado bom outra vez, retomou o serviço militar até o fim da guerra. Casini voltou aos estudos e, em 1919, acabava o curso liceal. Seu professor de língua italiana exortou-o a continuar pelo caminho das letras. Entretanto, Casini ingressava na faculdade de direito da universidade de Pisa. Passou um triênio à sombra da famosa "torre pendente", distinguindo-se entre os acadèmicos pelo estudo e por uma vida muito correta. Era então arcebispo de Pisa o cardeal Macchi, orador e cientista de renome, propulsor da Juventude Católica Universitária; o jovem acadêmico e ex-oficial de guerra entrou nas fileiras dos universitários católicos. Terminado o curso de direito em três anos, graças a um privilégio concedido pela lei do ensino aos excombatentes, Casini recolheu seus livros e voltou logo para Cornacchiaia. Doutorou-se em 1923.

Já dissemos que tinha pendor para as letras e tivemos ocasião de contar como disse adeus à advocacia, após ter defendido seu primeiro cliente. Seu sonho era escrever. Enviou um artigo ao jornal "L'Unità Cattolica" de Florença. Ao primeiro seguiram-se outros artigos e contos, publicados em 
jornais e revistas, que o tornaram conhecido de Giovanni Papini. Este "primeggiava nella repubblica dei letterati, non solo fiorentini, ma italiani, per non dire del mondo. Questi, sensibile ed abilissimo nell'avvertire le scosse che avrebbero apportati movimenti nuovi nelle lettere, subito fiutò nel giovane scrittore attitudini e meriti singolari. Si presentava con tanta modestia, ma con indizi sicuri del successo. Volle conoscerlo e gli dichiarò ruvidamente la propria stima invitandolo senz'altro a collaborare con lui. Per Casini fu quello un altro dei giorni che non si dimentican più.

Il Papini, che dirigeva la collana "I Libri della Fede", propose al Casini di tradurre per essa l'opera del De Maistre "Le Pape" e poi la vita di Pio X di René Bazin, ed egli accettò con entusiasmo.

Col Papini non tardarono ad apprezzare e stimare nella repubblica letteraria il nuovo arrivato molti altri scrittori cattolici: Domenico Giuliotti, Piero Bargellini, Guido Manacorda, Nicola Lisi, Raimondo Manzini.

Ormai aveva rinunziato con voto solenne e perpetuo all'avvocatura, aveva messo per sempre da parte la toga.

Il Papini, che aveva bisogno di un aiuto per il suo lavoro di biblioteca, chiese pure al Casini se voleva prestarsi a questo, e il Casini, che già da tempo si era stabilito a Firenze, fu per più mesi il suo "segretario fiorentino", come lo chiamava scherzando l'autore della Storia di Cristo" (9).

O encontro com Papini e com o grupo de escritores que rodeava "l'orco fiorentino" foi certamente proveitoso para Casini no sentido de que, destarte, teve logo aberto o caminho para publicar seus artigos e contos em revistas. No entanto, o grupo florentino não exerceu influência sôbre Casini de modo a determinar sua orientação artística e literária. $O$ jovem escritor tinha idéias e formação intelectual muito pessoais e continuou por um caminho absolutamente novo. Um dia, amigos pediram a Casini que publicasse em volume seus contos espalhados em revistas, especialmente em "La Festa" e "Il Carroccio". Foi assim que apareceu o primeiro livro di Casini: La Bella Stagione (10). O êxito fơ lisonjeiro e Ca- 
sini resolveu dedicar-se à literatura. De convicções sincera e profundamente cristãs, sua pena estaria a serviço de uma literatura inspirada nos princípios do catolicismo. Em Florença, no alto de sua cela, Casini escreveu estas palavras de sabor ascético:

Hic habitat in dulcedine cellae

Titus Casini Cornuclariensis.

O adjetivo "cornuclariensis" vem dizer-nos que Casini não podia esquecer os lugares de sua origem e dêles não podia viver afastado. A Cornacchiaia voltava freqüentemente e de sua aldeia, tomada como centro, ia passear pelas redondezas em busca de ar, de saúde, de amigos e de poesia. Um belo dia, chegou até o lugarejo chamado Frassignoni, do qual o escritor nos fala num capítulo do seu livro "Intermezzo" (14). Esse lugarejo devia tornar-se mui caro a Casini, depois de ter casado com Linetta Ayello, que lecionava aos meninos de Frassignoni. Casini é hoje um escritor lido e conhecido por tôda a Itália, mas continua, de certo modo, eternamente "cornuclariensis". Depois de ter morado por algum tempo em Frassignoni, pelas razões acima indicadas, passa agora sua vida entre Florença, Cornacchiaia, Sommaia e Firenzuola. Cada estação traz seus frutos e cada estação traz algum livro de Casini. Foi também êle um dos fundadores da famosa revista "Il Frontespizio", que teve na Itália anos de vida literária gloriosa, juntamente com Papini, Giuliotti, Bargellini, Lucatello e Lisi. A Casini, quando criança, chamavam "quello che ride sempre", aquêle que ri sempre.

"Ignaro - meglio, oblioso - dell'antica condanna, io godevo davvero il dono della vita e, recitando con mia madre ogni giorno le mie devozioni, potevo dir veramente: "Signore... vi ringrazio di avermi creato" tanto mi pareva bella la grazia di esistere.

Effetto ed espressione più naturale della gioia è il riso. $E$ io ho riso tanto durante la mia fanciullezza!... Ricordo che se qualcuno mi domandava una cosa, io non ero capace di rispondere senza ridere; ridevo a scuola, ripetendo alla maestra la mia 
lezione; ridevo - lo credereste? - perfino nel confessionale, mentre facero l'accusa de' miei peccati" (12).

Ainda hoje, depois de ter vivido tanto tempo, depois de ter conhecido as misérias da vida e da literatura, Casini é um homem contente, um homem que saboreia a alegria de viver. Parece ter sido um discípulo de Alexandre Manzoni, de quem aprendeu a sábia lição resumida pelo grande romancista lombardo nas famosas palavras saídas da bôca de Renzo e Luzia, os dois humildes protagonistas de "Os Noivos". Ao contar êles suas aventuras, concluíam dizendo que "Os dissabores vêm realmente, muitas vêzes, por se thes haver dado ocasião; mas que a conduta mais inocente não basta para os conservar distantes; e que, quando êles vêm, ou com culpa ou sem culpa, a confiança em Deus os abranda, e os torna úteis para uma vida melhor. Esta conclusão, se bem que tirada por gente humilde, afigurou-se-nos tão justa, que pensamos em pô-la aqui como o sumo de tôda a nossa história" (13).

O otimismo de Casini não é o de Lourenço, o Magnífico:

Chi vuol esser lieto, sia:

Di doman non c'è certezza (14).

Nem o humorismo de Casini é o de Shaw ou Villon, cujo riso é falso e morre na garganta. Seu humorismo, seu otimismo, brotam da fé inabalável naquelas palavras que os pais Ihe ensinaram na casa de pedra, em Cornacchiaia, trás os montes: "Meu Deus, dou-vos infinitas graças por me haverdes criado e feito nascer no grêmio da Igreja Católica" (15). Casini acredita em Cristo e, por isso, sabe que valor têm a morte e o sofrimento.

"Quanto a me, confesso che il riso sul labbro di chi non crede in Lui (Cristo), e di conseguenza crede in lei (a morte), mi rattrista come il più tragico dei controsensi, e non c'è nulla che mi lasci in definitiva l'anima pensosa e amara quanto i libri scritti per distrarre, da chi o per chi non abbia, verso la morte, altro rimedio che il distrarsi. L'umorismo, natura- 
lissimo e logico in bocca o nella penna di un cristiano, si chiami Manzoni o Chesterton, ha del macabro, per chi rifletta, in quella del semplice materialista, sia Voltaire o sia Shaw. Si ride con l'uno e con l'altro, si ride nella vettura Manzoni-Chesterton e in quella Voltaire-Shaw: ma lì è una brigata di amici che viaggia scherzando verso un paese desiderato $\mathrm{e}$ sognato: la vettura si fermerà un attimo al confine per la verifica dei documenti e la corsa riprenderà senza paragone più deliziosa; qui è un gruppo di avviati all'ultima pena che scherzando sembra si sforzino di non avvertire il ritmo sempre più accelerato con cui, incluttabilmente, senza speranza di grazia, si avvicinano al lugubre termine, di far credere misera vana vendetta contro il destino - che il termine non è temuto da loro" (16).

Graças a estas conviçõos, compreende-se porque, ainda hoje, depois de tanta experiência das coisas humanas, Casini é "quello che ride sempre". E também fica explicado como Casini, o autor de "Il Tempo e L'Eterno", não se envergonha de começar os dias indo à missa e terminar as tardes com a reza do têrço! Aliás declarou que até gosta de desempenhar o papel de coroinha, e uma das suas ambiçōes foi ser sacristão.

"Io gli (ao padre) servirò la messa... dopo avergli riempito e portato al posto le ampolline, acceso le candele e suonato l'entrata: tutte cose facili, anche per un letterato, e belle e importanti, come tutto quello che si fa per il Signore, e in ragion delle quali non nego di provare un certo piacere quando il ragazzo (o coroinha) non viene. Ciò per me, infatti, equivale a vedere, almeno in parte, almeno per un momento, avverato uno dei miei sogni più cari, esaudita una delle mie aspirazioni più vive: quella di fare il sagrestano" (17).

Casini levou para o trabalho literário a constância, a tenacidade do montanhês. Um após outro saíram de sua pena livros de contos, como: La Bella Stagione (1929), Al Fuoco e all'Ombra (1934); vidas de santos, como: San Vincenzo de' 
Paoli (1937), San Francesco Saverio (1940); contos bíblicos, como: II Poema dei Patriarchi (1932), Storia Sacra (1939); livros paroquiais, podemos assim apelidar La Parrocchia (1937), In Rosario (1938); e um volume muito original de caráter autobiográfico: Intermezzo (1942). Ùltimamente, Casini quis contar-nos também, de um modo popular, a Divina Commedia de Dante Alighieri.

A crítica italiana acolheu com bons elogios as obras casinianas e o autor tornou-se também discutido. Uns preferem os contos - La Bella Stagione, Al Fuoco e all'Ombra - , outros enaltecem o poeta de "Il Tempo e L'Eterno". E esta uma vasta "tetralogia" geórgico-litúrgica e constitui o trabalho de maior fôlego do autor. Do ponto de vista formal, talvez as melhores páginas casinianas sejam as dos contos. Revivem ai as figuras populares dos montes de Cornacchiaia, lendas de aldeia, momentos patéticos da vida familiar, inocentes travessuras da infância, os trabalhos do campo, as solenidades religiosas, as festas campesinas, as espertezas dos malanđros. Belas páginas, vivas páginas, páginas de vida vivida pela humanidade simples e humilde da fé e do trabalho. Alguns contos fazem pensar nas famosas novelas de Boccaccio pela frescura da narrativa: Giannigianni, La firma, Una cena troppo cara, Una cattiva mangiata. Estes dois últimos contos são obras-primas, sem mais nem menos, que as antologias italianas nunca deveriam preterir. Contam as trapaças de Goro Gori, lôbo, rapôsa e glutão ao mesmo tempo, um filante preguiçoso e vilão que exerce a profissão de comer os jantares dos outros.

Em "Una cattiva mangiata", Goro Gori está a caminho do convento dos frades para abiscoitar um bom almôço. Encontra um pobre autêntico que para lá se vai em busca de um pedaço de pão. Goro Gori disse, então, ao companheiro que se apresentasse ao convento como sendo Sidorio Biondi dal Cerro: êle diria ser Gigi da Califrè. Eram êstes dois benfeitores do convento. Graças a esta trapaça, receberiam êles o manjar dos amigos e não o pão sêco dos mendigos. O pobre não quis saber desta patifaria, mas Goro Gori não desistiu do propósito e zombava do simplório companheiro. Os dois 
andejos bateram à porta do mosteiro; Goro Gori falou como tinha pensado e o pobre também. Ambos foram recebidos e acomodados à mesma mesa.

"Dopo avere steso la tovaglia, messo i piatti, i bicchieri, le posate, le bottiglie del vino e dell'acqua, fratel portinaio, essendo già mezzogiorno, si segnò e disse l'Angelus, a cui anche Goro Gori rispose... (non sapendo far di meglio) con dei gran colpi di tosse.

Quando, di lì a poco, il frate ritornò con la marmitta della minestra, Goro Gori, ricordandosi che degli amici sta bene chieder le notizie:

"O il padre guardiano", domandò "come sta? Mi gli faccia tanti saluti".

"Sta bene", rispose il frate, levandogli nella scodella la minestra; "ora l'avviso che ci siete..."

'Non importa, sa, non importa", s'affrettò a riparar Goro Gori; "ci avrà da fare, e non voglio disturbarlo. Assai è lo scomodo che si dà venendo qui..."

"Ma che vi pare!" insistè il frate, "anche se si avesse da fare, i nostri benefattori vanno rispettati... Avverto anche fra Fedele, lo conoscete bene, eh? Ha finito ora la cerca del cacio lassù dalle vostre parti. Tornò ieri al convento e ora serve a tavola; ma anche lui ci ha più poco..."

Contro questi due gravissimi pericoli di venire scoperto, Goro Gori non vide altro scampo che quello di finir lui il desinare prima che finissero i frati, e poi con un pretesto qualunque scappar via, e chi s'è visto s'è visto.

Già, ma per finir presto di desinare bisognava che il frate facesse presto a portare in tavola le pietanze. $E$ invece il frate pareva non ne avesse punta della furia. 
Con le due scodelle vuote, una dentro l'altra, tra le mani, invece di andare a riportarle in cucina e portar oltre qualche cosa, il frate pareva indugiasse apposta, e, chiedi di quello, domanda di quell'altro, Goro Gori si sentiva già cascar le penne del pavone e s'imbrogliava a rispondere, complicando sempre più il suo caso.

"O di quel Goro Gori lassù del rostro paese, mi dite che cosa n'è? Ce ne parlava, giusto, tempo addietro, fra Fedele, che lui lo conosce bene, venendo alla cerca lassù, e sa di lui vita e miracoli..."

Goro Gori non ebbe da risponder cosa ne fosse di... Goro Gori, perchè il frate, rivolgendosi al suo compagno: "Un gran birbaccione, sapete, questo Goro Gori! Questo nostro benefattore, qui, che è del medesimo popolo, ve lo può dire: un gran birbaccione, un ingannatore famoso. Dico il vero?"

E Goro Gori a confermare - con che cuore ve l'immaginate - che Goro Gori era un gran birbaccione e un ingannatore famoso.

"Figuratevi", seguitò il frate, "che una volta, per rubare non so che somma a un de' suoi posti, lassù, si finse di raccoglier firme da mandare all'arcivescovo per chiedergli che non levasse a quel popolo un certo parroco. Con quest'inganno, va da uno che sapeva giusto fare appena la sua firma, gliela leva pari pari e poi nel bianco di quel foglio cosí firmato ci scrive un debito di quel tale verso di lui per... Per che somma se lo fece debitore?"

"Per cinquanta scudi", precisò Goro Gori.

"Per cinquanta scudi, capite? E raccontategli anche come l'andò a finire, voi che lo sapete bene. Io vo a portare in cucina questi cocci e a ripigliarvi qualche altra cosa." ... "Vado a avvisare il padre guardiano e fra Fedele che ci siete voi" (18).

Furioso e medroso, Goro Gori, depois que o frade se fôra para buscar mais iguarias, disse entre os dentes: "Vai para o 
inferno, fradeco do diabo!" $\mathrm{E}$ logo, pulando como um gatāo fugitivo, agarrou um pedaço de pão e, abocanhando outro de carne, deu às pernas. "Te lo meritavi, Goro Gori!"

Contista esperto e psicólogo da alma popular revela-se Casini. um realista, um "macchiaiolo", por vêzes, mas sem o sôpro desalentadoramente sentimental de Renato Fucini e sem a ironia amarga, tonitruante de Domenico Giuliotti. A veia narrativa casiniana faz pensar numa fonte de água fresca e límpida que jorra continuamente da pedra viva à sombra de verdes castanheiros, nem quente nem gelada, mas bem fresca para matar a sêde dos viajantes.

Não resta dúvida, no entanto, ao que nos parece, de que a porção literária de maior fôlego do escritor de Cornacchiaia - já o dissemos - está contida nos quatro volumes de "Il Tempo e l'Eterno": La Vigilia dello Sposo (1930), I Giorni del Castagno (1933), I Giorni del Ciliegio (1931), II Pane sotto la Neve (1935).

"La Vigilia dello Sposo" trata do tempo da quaresma e da primavera; "I Giorni del Ciliegio" são os dias da aleluia, isto é, do período litúrgico que vai da Páscoa até o Pentecostes e correspondem ao verão; 'I Giorni del Castagno" falam dos dias do outono, desde a festa da Trindade até o Advento; "Il Pane sotto la Neve" descreve-nos o tempo do Advento e do Natal, isto é, o período invernal.

t também a parte mais original da produção literária de Casini, e mesmo nova na literatura italiana. Nem em literaturas estrangeiras conhecemos obras semelhantes. Nestes quatro volumes passa diante dos nossos olhos a vida litúrgica da igreja, os trabalhos do campo, os santos do breviário, os costumes folclóricos toscanos, os heroísmos dos mártires antigos, as saudades familiares do autor, a vida dêste mundo e a do além. A história do passado revive no presente, os vivos falam com os mortos, a epopéia litúrgica da igreja está entrelaçada com os trabalhos rústicos de todos os dias. Casini saboreia tudo: as neves do inverno e as sebes floridas da primavera, os trigais lourejantes sob os bafejos quentes do verão e as imensas tristezas do outono; descreve as coisas da terra 
e os festins do céu, o tempo e a eternidade. Um universo, afinal, está descrito nestas mil duzentas e setenta páginas. Um universo em que há lugar para tudo e para todos: para o latim de Horácio e de Virgílio, para os ermitōes do deserto e as façanhas do diabo, para as virgens do calendário e para as damas dos castelos, para os camponeses de foice na mão e para os generais do exército. Livro de história e de poesia ao mesmo tempo, breviário e calendário. Falando do calendário, escreveu Casini: "Il Calendario è, fuori di dubbio, un libro, e non dico per la forma - che può anche non esser tale bensí per la sostanza. Un libro universale, non perchè tutti i popoli lo abbiano o si pubblichi in tutte le lingue o si trovi in ogni casa e quasi indosso a ciascuno, ma ben più a ragione, perchè libro d'ogni scienza e d'ogni lettore" (19). Neste livro - o livro de todos - o historiador pode ler a história, e não qualquer história particular, mas a universal; o filósofo encontra aí muitos colegas seus; o político, de qualquer partido, aristocrata ou democrata, republicano ou comunista, pode achar em suas páginas matéria de meditação para o govêrno das coisas humanas; o legislador terá aí um código de leis e o poeta imensa fonte de inspiração.

Pois bem, tudo isto é a vasta tetralogia que Casini foi compondo com muita erudição e abundante suor: o livro de todos.

Nessa tetralogia Casini revela-se poeta geórgico e cristão. Virgílio foi sempre um dos seus afetos. Ama o "pius" Virgilio porque cantou aos Romanos a terra e a religião, as fontes inspiradoras da poesia casiniana. Virgílio cantou aos latinos a mitologia pagã, Casini canta aos cristãos de hoje a liturgia católica.

"Egli - escreve Monticone em formoso ensaio sôbre 'Il Tempo e L'Eterno" - col suo animo di cristiano e di poeta, sa accogliere e godere tutta la bellezza della religione, anche in ciò ch'essa ha di esterno e di visivo.

La vicenda delle stagioni, l'amore delle fatiche georgiche, la gioia dei fiori e dei frutti campestri, la virgiliana bontà delle greggi e dei pastori, si armonizzano con immediata cor- 
dialissima spontaneità alla vicenda liturgica delle feste della sua Pieve, all'intimo dramma o all'intimo idillio delle anime fraterne della sua Parrocchia, e da cotesto connubio nascono sotto la sua penna squisita le inimitabili meraviglie de' suoi racconti georgico-liturgici... Nelle descrizioni dei paesaggi in relazione alle funzioni religiose, è tal freschezza e naturalezza, che, alle volte, coll'animo e col cuore, leggendo, quasi quasi si allargherebbero pure i polmoni per respirare l'aria balsamica della campagna, attraverso la quale si snoda la processione, o passa il viatico, o un corteo nuziale" (20).

Casini teve, pois, uma intuição nova ao escolher o ano litúrgico da Igreja católica como matéria de sua obra poética. Saiu de sua pena uma epopéia formosa. Lendo os quatro volumes, vemos passar diante de nós a sucessão das estações do ano, cada uma trazendo seus frutos para o sustento de nossa vida corporal, e também o revezar-se dos ciclos litúrgicos que alimentam a vida do espírito, lembrando-lhe seus destinos superiores.

Casini é profundamente humano; antes de ser literato sabe que deve ser homem. Para êle a literatura é uma vocação como qualquer outra, e tem a finalidade de servir à humanidade. Ser pedreiro sòmente por ser pedreiro, é coisa que não tem sentido; da mesma forma, Casini pensa que ser literato sòmente por ser literato é coisa perfeitamente inútil. Como a colher de pedreiro constrói as casas para a felicidade do corpo, assim a pena do escritor deve construir livros para a felicidade do espírito. O lavrador rasga sulcos no campo para dar alimento corporal ao próximo, o literato deve "trar con la penna solchi e solchi di parole attraverso la pagina bianca" (21) para dar alimento intelectual ao espírito.

Vida intensa e benfazeja, como se vê, a de Casini, escritor por vocação. Seus volumes são muitos e bem construídos. Casini pensa em tudo, e pensa longamente antes de escrever. Dizem seus amigos que, às vêzes, passa horas antes de colocar uma virgula, e dias inteiros para limar um período. Escreve com o lápis, aos pulos, por causa da ferida no braço direito, herança ingrata mas gloriosa da primeira guerra mundial. 
Depois, passa a limpo com a máquina de escrever e quando seus "flogliettacci" - como êle diz - saem para a tipografia não precisam mais de correções. Original até nas capas dos seus livros. Falamos das edições da "Libreria Editrice Fiorentina" (22), tão vivas com as xilografias no alto e os títulos grandes, coloridos, domésticos, ocupando tôda a capa e cheirando a frutas. Em suas xilografias sempre brilha algum luzeiro do céu ou da terra, frondeja alguma árvore, despontam montanhas ao longe, andam procissōes de lavradores e carvoeiros, de orantes de chapéu na mão, ou então algum padre oficiante ladeado pelo povo cristão.

O amor às letras não fêz de Casini um misantropo ou um altivo, afastado da vida de todos os dias. Nada disso. O mundo pode voar em estilhaços pelos ares, mas Casini não perderá sua serena tranqüilidade, seu habitual bom humor. Nem deixa de praticar, freqüentemente, as obras de misericórdia corporal para com o próximo. Pelo contrário, acha nisto uma satisfação profunda e até inspiração para seus contos literários.

"Di tanto in tanto, quando il mal della carta - il male dei poveri letterati - m'ha più indisposto, per rimettermi in salute io monto in tram e vado a Careggi... il sanatorio per i malati di petto...

Anch'io ho, infilato al dito, il mio piccolo involto, che poserò, fra una bambola, una madonnina di Lourdes, uno specchietto rotondo e una bottiglia di calmante, sul comodino accanto al letto $216 \mathrm{~b}$.

E il letto di Cesarina, che non è proprio mia parente, ma è del mio popolo: ha preso il nome al medesimo fonte dove lo presi io; ha risposto nella medesima chiesa, con la medesima aria, alle medesime preghiere del medesimo parroco; è passata, andando a messa, davanti al mio uscio; ha baciato per via i medesimi tabernacoli; ha nel cuore - io ne son sicuro -, come se li avesse davanti agli occhi, i medesimi poggi, i medesimi castagneti, il modesimo fiume, il medesimo cielo che ho nel cuore io" (23). 
Assim é Tito Casini: bom literato e cristão praticante, homem de coração aberto à poesia da vida real, cantor do povo humilde, religioso e trabalhador. Há um capítulo em "Il Pane sotto la Neve" intitulado "Fedeltà" "Fidelidade". Fidelidade a que? A Cornacchiaia e a tudo que sua terra representa para êle. Muitos pensavam que o literato não ficasse fiel ao seu rincão. Elle demonstrou, entretanto, que se conservou fiel àquele mundo: mundo da natureza, da religião, da poesia. A sombra dos bastos castanheiros do vale do Santerno, ao lado da tôrre companária de Cornacchiaia, perto do pilar da Regina Agretis, êle conversa com o tempo e com a eternidade. Até quando estas conversações continuarem, êle haverá de enriquecer a literatura italiana de formosas e sábias páginas de poesia.

Assim vemos, através de suas obras,

Titus Casini cornuclariensis. 


\section{$-24-$ \\ BIBLIOGRAFIA}

1) Tito CASINI, Al fuoco e all'ombra, L. E. F., Florença, 1946, p. 82.

2) Tito CASINI, Il pane sotto la neve, L. E. F., Florença, p. 83. Cornacchia = gralha. Cornacchiaia faz pensar em "lugar das gralhas", ou em "grande quantidade de gralhas".

3) Severino MONTICONE, Tito Casini dalle sue opere, P. S. S. P., Alba, 1943, p. 16.

4) Tito CASINI, I giorni del ciliegio, L. E. F., Florença, 1940, p. 244.

5) Tito CASINI, Al fuoco e all'ombra, cit., p. 170.

6) Tito CASINI, Ibidem, pp. 172-173.

7) Severino MONTICONE, Tito Casini dalle sue opere, eit., pp. 31-33.

8) Idem, ibidem, p. 46.

9) Idem, Ibidem, pp. 58-59.

10) O título do livro foi sugerido por Papini, e o volume foi publicado pela L. E. F., Florença, 1929.

11) Cap. III - Memorie di Frassignoni, pp. 83-138.

12) Tito CASINI, La bella stagione, L. E. F., Florença, 1942, pp. 273-274.

13) Alexandre MANZONI, Os Noiros, tradução por Luís LEAL FERREIRA, Vozes, Petrópolis, 1951, p. 523.

14) Lorenzo DE' MEDICI (IL MAGNIFICO), Trionfo di Baceo e Arianna, vv. 3-4.

15) Casini escreveu também um Catechismo popolare in versi, publicado na coleçāo "Carro di San Giovanni".

16) Tito CASINI, Intermezzo, L. E. F., Florença, 1942, pp. 56-57.

17) Tito CASINI, Intermezzo, cit., p. 17.

18) Tito CASINI, La bella stagione, cit., pp. 41-43.

19) Tito CASINI, La vigilia dello Sposo, L. E. F., Florença, 1935, p. 27.

20) Severino MONTICONE, Tito Casini dalle sue opere, cit., pp. 87-88

21) Tito CASINI, I giorni del ciliegio, cit., p. 7.

22) As obras de Tito Casini estão sendo publicadas, agora, pela "Società Editrice Internazionale", de Turim, em edição muito luxuosa e esmerada. No entanto, as edições da L. E. F. de Florença, tinham feiçāo tipográfica mais artística e muito original.

23) Tito CASINI, Al fuoco e all'ombra, cit., pp. 185-187.

Casini traduziu também muitos livros. Lembramos aqui a tradução da obra monumental de P. COSTE, Saint Vicent de Paul - Le Grand

.... Saint du Grand Siècle. O titulo da tradução italiana é: Il Grande Santo del Gran Secolo - Il Signor Vincenzo, Roma, 1934, 3 vs., pp. 1570. 